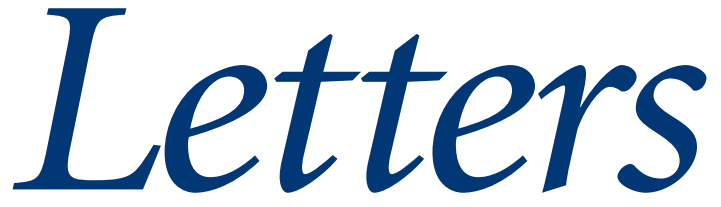

All letters are subject to editing and may be shortened. Letters should be sent to the BJGP office by e-mail in the first instance, addressed to journal@rcgp.org.uk (please include your postal address). Alternatively, they may be sent by post as an MS Word or plain text version on CD or DVD. We regret that we cannot notify authors regarding publication. Letters not published in the Journal may be posted online on our Discussion Forum. For instructions please visit: http://www.rcgp.org.uk/bjgp-discuss

\section{Deep venous thrombosis}

We thank Dr Reynolds ${ }^{1}$ for carefully reading and commenting on our article, ${ }^{2}$ and indeed must agree that the maximum score on the Oudega rule is 13 points (as a patient cannot be both male and taking oral contraceptives). We do stress, however, that from a GP's point of view, the most valuable use of the Oudega rule is to exclude deep venous thrombosis (DVT). For that purpose, a threshold at three points or fewer (please note, this automatically includes a negative D-dimer test) is safe for excluding DVT in primary care. Using a point-of-care $\mathrm{D}$-dimer test, it is even possible to safely exclude DVT during the consultation of the patient. Hence, with the use of the Oudega rule and a point-of-care D-dimer test, DVT management has now definitely entered the realm of primary care.

\section{Geert-Jan Geersing,}

University Medical Center Utrecht, Julius Center for Health Sciences, Universiteitsweg 100, Utrecht, 3584 CG, Netherlands. E-mail: G.J.Geersing@umcutrecht.nl

\section{Kristel Janssen,}

University Medical Center Utrecht, Julius Center for Health Sciences and Primary Care, Netherlands.

\section{Ruud Oudega,}

University Medical Center Utrecht, Julius Center for Health Sciences and Primary Care, Netherlands.

\section{Henk CPM van Weert,}

Academic Medical Center, University of Amsterdam, Netherlands.

\section{Henri EJH Stoffers,}

Maastricht University Medical Center, CAPHRI School for Public Health and Primary Care, Netherlands.
Arno W Hoes,

University Medical Center Utrecht, Julius Center for Health Sciences and Primary Care, Netherlands.

\section{Karel GM Moons,}

University Medical Center Utrecht, Julius Center for Health Sciences and Primary Care, Netherlands.

\section{REFERENCES}

1. Reynolds G. Diagnostic classification in patients with deep venous thrombosis. Br J Gen Pract 2011; 61(582): 63.

2. Geersing G-J, Janssen K, Oudega R, et al. Diagnostic classification in patients with suspected deep venous thrombosis: physicians' judgement or a decision rule? $\mathrm{BrJ}$ Gen Pract 2010; 60(579): 742-748.

DOI: 10.3399/bjgp11X556308

\section{Self-monitored blood pressure measurements}

We appreciate Dr O'Connors interest in our study, but do not agree with his comments. ${ }^{1}$

Studies should be sized for their purpose. In this case, 163 participants provided reasonably narrow confidence intervals around the coefficients of variation (CV) estimate, for example; for systolic office blood pressure (BP) $8.6 \%(95 \% \mathrm{Cl}=$ 7.6 to $9.6 \%$ ). We feel this interval excludes any meaningfully different clinical interpretation.

Regarding participant selection, few studies select people randomly from the population. Studies of BP almost always select people whose BP is considered clinically relevant - typically, with established hypertension, cardiovascular disease, or risk factors, as in this study. In clinical practice, most patients for whom accurate BP measurement is thought desirable will fall into one of these categories.
The Boso Medicus and Boso Medicus Prestige devices are rebrandings of the A\&D UA-767 and UA-787 devices (Welte W, Bosch \& Sohn GmbH. Personal communication, 2010), that are listed on the British Hypertension Society website. ${ }^{2}$ We apologise for this omission.

The CV is the standard way of reporting variability because it allows comparison of variability between samples with different means for example, hypertensive and nonhypertensive patients.

It is not clear how Dr O'Connor prefers the trial data to be explained. We could present the actual BP measurements for individual participants, but BP could be made to appear more or less variable simply by selecting participants with labile or relatively stable BP. The use of a summary statistic for the entire dataset is inevitable if such bias is to be avoided. We felt some interpretation of the CV would be helpful, and this can be applied to real patients as well as hypothetical ones.

Our results are in line with other studies as referenced in our paper. ${ }^{3}$ We can provide further reassurance from our unpublished analyses of other datasets, that have yielded CV estimates between $7.4 \%$ (for a well-known trial with several thousand uncomplicated participants) and $11.6 \%$ (for complex patients with imperfect real-life BP measurement). The variability of office BP quoted in this study is likely to be rather conservative, as many clinicians do not have time to measure BP in triplicate after 5-minutes at rest.

\section{Roderick E Warren,}

Royal Devon \& Exeter NHS Foundation Trust, Barrack Road, Exeter, EX2 5DW. E-mail: roderick.warren@nhs.net

Tom Marshall,

Unit of Public Health, University of Birmingham. 
Paul L Padfield,

Metabolic Unit, Western General Hospital, Edinburgh.

\section{Sigrun Chrubasik,}

Institute of Forensic Medicine, University of Freiburg, Germany.

\section{REFERENCES}

1. O'Connor R. Self-monitored blood pressure measurements. Br J Gen Pract 2011; 61(582): 63.

2. British Hypertension Society. Automatic blood pressure measuring devices suitable for use in the clinic and also at home for self-monitoring. Leicester: British Hypertension Society. http://bhsoc.org/bp monitors/ automatic.stm (accessed 11 Jan 2011).

3. Warren RE, Marshall T, Padfield PL, Chrubasik S. Variability of office, 24-hour ambulatory, and selfmonitored blood pressure measurements. Br J Gen Pract 2010; 60(578): 675-680.

DOI: 10.3399/bjgp11X556317

\section{Junior response to the global health editorial}

As trainees and new GPs, we warmly welcome BJGP's new International Advisory Board and plans to increase its emphasis on the international perspective of primary care. ${ }^{1}$ We also read with interest the editorial highlighting the role that primary health care can play in the field of global health. ${ }^{2}$ This comes at a moment when the need for undergraduate and postgraduate education in global health is increasingly recognised, such as by the recent Lancet Commission on the education of health professionals for the 21 st century $^{3}$ and BMJ's editorial on training programmes in global health. ${ }^{4}$ The extent of the political capital given to this issue was highlighted at the House of Lords on 20 December $2010,{ }^{5}$ when a debate led by Lord Crisp challenged the government on how they will ensure that the subject of global health is included in the education of all health professionals.

Benefits of gaining an international perspective on health care are manifold; offering personal and professional learning opportunities for those involved. There are also benefits to be gained by the NHS as a whole, as emphasised in the Department of Health's framework for NHS involvement in international development. The importance of the UK contribution to global health has been highlighted in various other documents including the Crisp Report, ${ }^{7}$ Health is Global, ${ }^{8}$ the Tooke Report, ${ }^{9}$ and the Gold Guide. ${ }^{10}$

Some work is already underway; the UK medical student group MedSIN has produced a consultation document, based on the GMC's Tomorrows Doctors, that drafts specific global health learning outcomes for undergraduates. ${ }^{11}$ The Alma Mata Global Health Graduates' Network ${ }^{12}$ has also developed a proposal for postgraduate training in global health, due to be published in Clinical Medicine later this year. In general practice there is a rapidly expanding WONCA worldwide network of trainee and new GPs through the Vasco da Gama (Europe), Rajakumar (Asia-Pacific), and Waynakay (IberoAmerica) Movements, as well as an increasing number of AiTs and First5 GPs expressing an interest in international primary care through the RCGP Junior International Committee. Furthermore, a nascent group linking juniors involved in global health at the various UK Royal Colleges is gathering momentum. However, these efforts will need high-level support in order to effect change in an educational system that has not kept pace with the challenges of the 21 st century.

The World Health Report of $2008^{13}$ underlined the importance of primary health care; 'now more than ever', and reminded us of the 1978 Alma Ata $^{14}$ declaration. This recent surge of activity confirms a consensus that health professionals in the UK are not being adequately prepared for current and future global health challenges. As Lord Crisp highlighted, there is a lot of interest and agreement on this issue, "what we need now is some action.'

\section{Luisa Pettigrew,}

First5 GP, Randolph Surgery,

235a Elgin Avenue, London, W9 $1 \mathrm{NH}$.

E-mail: luisapettigrew@hotmail.com

\section{Jessica Watson,}

GP ST2, Academic Clinical Fellow, Academic Unit of Primary Health Care, University of Bristol.
Emily Spry,

GP ST3, London

Reem Hasan,

First5 GP, Grays Inn Medical, London.

Ha-Neul Seo,

GP ST3, Statham Grove Surgery, London.

Rue Roy,

GP ST2/ST3, Clinical Advisor on the Chief Medical Officer's Advisor Scheme, London.

\section{Mbang Ana}

First5 GP, Clinical Teaching Fellow, Barts \& The London School of Medicine \& Dentistry, London.

\section{Soleman Begg,}

GP ST3, Kepier Medical Practice, Houghton Le Spring.

Jennifer Hall,

ST4, Intercollegiate Global Health Junior Doctors Working Group Chair and Faculty of Public Health's International Health Trainees' Group Chair, London.

\section{Colin Brown,}

Alma Mata Global Health Graduates' Network Working Group \& Academic Clinical Fellow in Infectious Diseases \& Microbiology, King's College, London.

\section{REFERENCES}

1. Jones R. The 7 International Advisory Board. Br J Gen Pract 2010; 60(581): 881 .

2. De Maeseneer J. The contribution of primary health care to global health. Br J Gen Pract 2010; 60(581): 875-876.

3. Frenk J, Chen L, Bhutta Z, et al. Health professionals for a new century: transforming education to strengthen health systems in an interdependent world. Lancet 2010; 376(9756): 1923-1958.

4. Vermund $\mathrm{SH}$, Audet CM, Martin MH, Heimburger DH Training programmes in global health. BMJ 2010;341: c6860.

5. House of Lords. Table of contents for Monday 20 December 2010. NHS: global health. Question for short debate. http://www.publications.parliament.uk/pa/ ld201011/ldhansrd/text/101220-0002.htm\# 10122019000667 (accessed 11 Jan 2011).

6. Department of Health. The framework for NHS involvement in international development. London: Department of Health, 2010. http://www.dh.gov.uk/en/ Publicationsandstatistics/Publications/PublicationsPolicy AndGuidance/DH 117137 (accessed 11 Jan 2011).

7. Crisp N. Global health partnerships; the UK contribution to health in developing countries. Department of Health, 2010. http://www.dh.gov.uk/en/Publicationsandstatistics/ Publications/PublicationsPolicyAndGuidance/DH_0653 74 (accessed 11 Jan 2011).

8. Department of Health. Health is global; proposals for a government wide strategy. Department of Health, 2010. http://www.dh.gov.uk/en/ Publicationsandstatistics/ Publications/PublicationsPolicyAndGuidance/DH_0726 97 (accessed 11 Jan 2011).

9. Tooke J. Aspiring to excellence; findings and final 